\title{
Determination of the prevalence of Salmonella spp. and $S$. aureus in meat products by Real-Time PCR and testing their antibiotic susceptibility*)
}

\author{
REYHAN IRKIN ${ }^{1}$, BERKAY BOZKURT ${ }^{2}$, GULENDAM TUMEN $^{2}$ \\ ${ }^{1}$ Department of Nutrition and Dietetics, Faculty of Health Sciences, Izmir Democracy University, Izmir, Turkey \\ ${ }^{2}$ Department of Biology, Faculty of Science and Letters, Balikesir University, Balikesir, Turkey
}

Irkin R., Bozkurt B., Tumen G.

Determination of the prevalence of Salmonella spp. and $S$. aureus in meat products by Real-Time PCR and testing their antibiotic susceptibility

\section{Summary}

From a public health point of view meat products contain high pathogenic risk factors. This is because they can be contaminated with Salmonella spp. and Staphylococcus aureus microorganisms, and, more importantly, antibiotic resistance has been reported in these microorganisms at an increasing frequency. To examine the presence of Salmonella spp. and Staphylococcus aureus in samples of raw and semi-cooked (chicken doner, meat doner, chicken, beef, and lamb products) meat from markets of Izmir and Balikesir, Turkey were analysed. The presence of microorganisms in the samples was determined by Real-Time PCR method using Salmonella spp. and $S$. aureus specific primers. Following Real-Time PCR, microorganisms were isolated by selective culture methods and biochemical tests from the positive meat samples and tested for their antibiotic susceptibility using the Kirby-Bauer Disk Diffusion Method. The antibiotic disc diffusion method showed that $S$. aureus was resistant to penicillin $G$, oxytetracycline, sulfamethoxazole, tetracycline, erythromycin, and ampicillin, whereas Salmonella spp. was resistant to penicillin G, sulfamethoxazole, erythromycin, and ampicillin. As these products are consumed frequently, their contamination with $S$. aureus $\left(\geq 5 \times 10^{3} \mathrm{cfu} / \mathrm{g}\right)$ and $S a l m o n e l l a$ spp. can be a risk factor for food poisoning. The contamination of meat products' with $S$. aureus and Salmonella spp. can be a risk factor for public health and the antibiotics to be preferred in illness treatment are of critical importance.

Keywords: Staphylococcus aureus, Salmonella spp., Real-Time PCR, meat products, antibiotic sensitivity

Sufficient nutrition is essential to maintain a healthy life and enjoy protection from diseases. The reliability of the foods consumed is a major factor for tissue growth, regeneration, and the fruitful functioning of our bodies. A great majority of the nutrition quantity required for our body is provided by meat products. However, many food products, especially animal source foods, are convenient for contamination by pathogenic microorganisms. If the compulsory hygiene rules are not followed in the process extending from production to sale, undesirable microorganisms infect and spread in the food and the consumption of infected foods brings with it many health problems (40).

Food poisoning, which is caused by microorganisms transported through foods, is one of the most common global health problems, affecting many people around

*) This study was supported by Balikesir University Scientific Research Projects Unit (BAP 2016-2018/05). the world every year. Even though it only appears to affect people's health, it also has an economic impact on countries. Two of the most commonly identified species related to food infections are Salmonella spp. and Staphylococcus aureus (S. aureus) (23). Salmonella is one of the most common pathogenic microorganisms and causes foodborne outbreaks and infections that are known as salmonellosis in many countries. Cross-contamination, which is the transmission of microorganisms from a contaminated surface to a noncontaminated surface between human, environmental factors and foods, mostly leads to diseases such as salmonellosis (33). Salmonella is considered to be a risk factor for the consumer, even in low amounts. For this reason, it is not allowed to be present in food products. S. aureus is another pathogenic microorganism frequently encountered in food contaminations. The majority of food poisoning is caused by entero- 
toxins produced by $S$. aureus strains as a by-product during growth, and is a significant global threat to human health (16).

The rapid and cost-effective diagnosis of foodborne pathogens throughout the food chain is an important issue for the industry and public health. Real-Time PCR (qPCR) is the preferred molecular technique as it can detect and quantify the amount of the targeted microorganisms with high specificity and sensitivity. It is also a reliable method as it can generate both qualitative and quantitative data about specific targeted microorganisms in a short period of time. Real-Time PCR analysis, which allows for rapid detection even in a small amount of bacterial DNA, has many advantages over other types of microorganism detection, regardless of the type and growth physiology of the microorganism $(11,43)$.

It is not always possible to identify the food types causing food poisoning, but unlike red meats, poultry meat contains a large percentage of reported foodborne pathogens such as Campylobacter spp. and Salmonella spp. (20). Day by day, the antimicrobial drug resistance of microorganisms is increasing because of the therapeutic applications in animal husbandry. The usage of antibiotics in inappropriate doses and time intervals as feed additives results in the development of resistant strains. Furthermore, animal-derived foods which contain antibiotic residues can lead to poisoning, allergies, and disruption in the human gut flora after consumption $(6,13,24,27)$. Importantly, it is more challenging to deal with pathogens that display multidrug resistance than with normal ones when treating infections. To improve food safety planning and infection-specific treatment strategies, it is necessary to observe the prevalence and antimicrobial resistance of pathogenic microorganisms in consumed food either raw or semi-cooked. The objective of this study is to assess the meat samples collected from the Izmir and Balikesir markets in terms of their contamination with Salmonella spp. and S. aureus strains and to evaluate antibiotic resistance profiles of these strains.

\section{Material and methods}

Sample collection. The study sites are the Balikesir and Izmir provinces located in the west of Turkey (Fig. 1). In

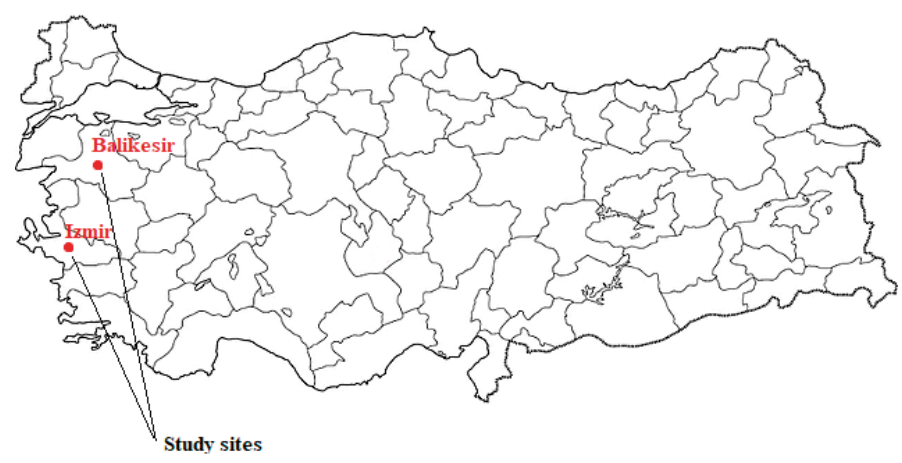

Fig. 1. Areas of the study the present study, raw (chicken, beef, and lamb products) and semi-cooked (chicken and meat doner) samples were used. For semi-cooked products, generally a heat treatment below 100 degrees is applied in Turkey. Samples were collected from various bazaars (10), local markets (40), and large hypermarkets (50) to represent distinct production companies in the Izmir and Balikesir provinces randomly between April 2017 and September 2017. A total number of 100 samples that include 25 raw chicken meats, 25 raw red meats, 25 semi-cooked chicken meats, and 25 semi-cooked red meats, were collected in sterile bags. After being brought to the laboratory under cold chain conditions, the samples were marked according to date and area and processed $2 \mathrm{~h}$ after collection. For the prevention of cross-contamination throughout sampling, sterile gloves and equipment were used.

Enrichment procedures. First, samples were cut into small pieces $(25 \mathrm{~g})$ with a sterile scalpel. In pre-enrichment, $25 \mathrm{~g}$ of each of the meat samples were aseptically transferred into $225 \mathrm{~mL}$ of buffered peptone water (BPW) (Merck, Germany). Homogenised samples were incubated for 18 hours at $34-38^{\circ} \mathrm{C}$. For isolation of both Salmonella and $S$. aureus, a part of BPW was then transferred to different enrichment media.

Isolation of Salmonella. The $0.1 \mathrm{~mL}$ and $1 \mathrm{~mL}$ of preenrichment culture were transferred into $10 \mathrm{~mL}$ of Rappaport Vassiliadis Medium (RVS) Broth (Merck, Germany) and Muller Kauffman Tetrathionate Novobiocin Broth (MKTTn) (Merck, Germany) respectively. Next, $24 \mathrm{~h} \mathrm{incu-}$ bation was performed for RVS at $42^{\circ} \mathrm{C}$, and for MKTTn at $37^{\circ} \mathrm{C}$. Each selective enrichment culture was transferred to Xylose Lysine Desoxycholate (XLD) Agar (Merck, Germany) and Bismuth Sulphite Agar (BSA) media (Merck, Germany) on the following day. Plates were incubated at $37^{\circ} \mathrm{C}$ for 24 hours to isolate the visible colonies (22). Displayed pink-red colonies with a black centre in XLD agar and brown-grey-black colonies with a bright metallic centre in BSA media were considered to be Salmonella. For the confirmation, API 20E system (bioMérieux, Marcy-l'Étoile, France) was used according to the manufacturer's protocol.

Isolation of $\boldsymbol{S}$. aureus. For $S$. aureus isolation, firstly $10^{1}$ dilutions were prepared from pre-enrichment culture. Next, Baird-Parker Agar (Merck, Germany), which is a selective medium due to its egg yolk emulsion and tellurite components, was utilised for $0.1 \mathrm{~mL}$ of dilution samples inoculation (15). Plates were incubated at $37^{\circ} \mathrm{C}$ for 24 hours to isolate the visible colonies. After 24 hours of incubation, the colonies that formed a black or grey transparent zone and had a bright and smooth appearance were accepted as $S$. aureus. Confirmation was performed by coagulase test and API Staph (bioMérieux, Marcy-l'Étoile, France) according to the manufacturer's protocol.

DNA isolation. Taking $1 \mathrm{ml}$ of the pre-enrichment culture, DNA isolation was carried out using the High Pure PCR Template Preparation Kit (Roche Applied Science, Germany), a commercial DNA extraction kit, according to the manufacturer's protocol. The concentrations and purities of the DNAs obtained after isolation were measured by the Nanodrop and the DNAs were maintained at $-20^{\circ} \mathrm{C}$ for the next step. 
Tab. 1. Primers and probes for Real-Time PCR amplification

\begin{tabular}{|c|l|l|l|}
\hline \multicolumn{1}{|c|}{ Microorganism } & \multicolumn{1}{|c|}{ Primer Name } & \multicolumn{1}{|c|}{ Sequence (5'-3') } & \multicolumn{1}{c|}{ Probe } \\
\hline \multirow{2}{*}{ Salmonella spp. } & Forward & CTCACCAGGAGATTACAACAT & 5' FAM-CACCGACGGCGAGACCGACTTT-TAMRA 3' \\
& Reverse & AGCTCAGACCAAAAGTGACCA & \\
\multirow{2}{*}{ Staphylococcus aureus } & Forward & AATTAACGAAATGGGCAGAAACA & 5' FAM-AGAAATTAACTGGATGGTACGCGCGAAGA-TAMRA 3' \\
& Reverse & TGCGCAACACCCTGAACTT & \\
\hline
\end{tabular}

Real-time PCR analysis. Real-time PCR and data analysis were performed in Roche LightCycler ${ }^{\circledR} 480$ II real-time detection system (Roche Applied Science, Germany) using LightCycler $^{\circledR} 480$ Probes Master 2x (Roche Applied Science, Germany). First, from isolates of $S$. aureus (ATCC 25923) and Salmonella spp. (ATCC 700623), cloning was performed using the $\mathrm{TOPO}^{\circledR}$ TA Cloning Kit (Invitrogen, Carlsbad, CA). After the cloning, $10^{9}$ standards of plasmids were diluted until there were a total of $10^{1}$ copies which were prepared and the standard curve was drawn using these standards. PCR amplification was performed with the Salmonella spp. (30) and S. aureus (28) specific primer pairs and TaqMan probes (Tab. 1) using an in-house protocol. Primers were synthesised by Macrogen (Korea). The mixture contained $10 \mu \mathrm{L} 2 \mathrm{x}$ LightCycler ${ }^{\circledR} 480$ Probes Master; $1 \mu \mathrm{L}$ of each primer; $0.4 \mu \mathrm{L}$ of each TaqMan probe; $5 \mu \mathrm{L}$ DNA template. To reach a total volume of $20 \mu \mathrm{L}$ per well, distilled water was added. Thermal cycling conditions were as follows: $95^{\circ} \mathrm{C}$ for $10 \mathrm{~min}$, followed by 45 cycles of $95^{\circ} \mathrm{C}$ for $10 \mathrm{~s}, 60^{\circ} \mathrm{C}$ for $30 \mathrm{~s}$, and $72^{\circ} \mathrm{C}$ for $1 \mathrm{~s}$. All runs included a negative control without target DNA and a standard.

The Roche LightCycler ${ }^{\circledR} 480$ II Real-time PCR detection system and software were used for data analysis. The system records crossing point (Cp) number when fluorescence crosses a specific threshold value in the exponential phase of amplification. The $\mathrm{Cp}$ value is a measure of the quantity of transcript of interest. Thus, we have calculated unknown sample concentrations depend on $\mathrm{Cp}$ values and standard curve.

Antimicrobial susceptibility testing. Antibiotic susceptibilities were determined by Kirby-Bauer Disk Diffusion method (4) according to the Clinical and Laboratory Standards Institute (CLSI) guidelines (7). The typical colonies of both Salmonella spp. and S. aureus were diluted in sterile BPW and the McFarland turbidity was adjusted to a standard 0.5. Standardised suspension cultures were inoculated in Plate Count Agar (PCA) plates equally. Antibiotic discs were placed with at least a $15 \mathrm{~mm}$ gap to prevent overlapping of the zones on the plates and incubated at $37^{\circ} \mathrm{C}$ for 18 hours. Susceptibility to the following 10 antimicrobials were tested: chloramphenicol $(30 \mu \mathrm{g})$, penicillin $\mathrm{G}(10 \mathrm{U})$, bacitracin $(10 \mathrm{U})$, oxytetracycline $(30 \mu \mathrm{g})$, sulfamethoxazole $(25 \mu \mathrm{g})$, neomycin $(30 \mu \mathrm{g})$, novobiocin $(30 \mu \mathrm{g})$, tetracycline $(30 \mu \mathrm{g})$, erythromycin $(30 \mu \mathrm{g})$, and ampicillin $(10 \mu \mathrm{g})$ (Oxoid, Basingstoke, UK). After incubation, the zone diameters around the antibiotic discs were measured with a ruler, and sensitivity and resistance profiles of microorganisms to antibiotics were determined as susceptible, intermediate, or resistant according to the CLSI guidelines (7).

Statistical analysis. The data were analysed using chisquare $\left(\chi^{2}\right)$ tests, contingency tables. When interpreting the results, $\mathrm{p}<0.05$ was considered statistically significant.

\section{Results and discussion}

Samples of raw and semi-cooked meat, either sourced locally or imported, were purchased from different locations in Balikesir and Izmir provinces. A hundred samples of meat were used in this study. Samples were examined using Real-Time PCR analysis in terms of the presence of Salmonella spp. and S. aureus, and microorganisms' resistance profiles were determined in 10 different antibiotics by disk diffusion method in samples with undesirable levels of bacteria according to the Turkish Food Codex.

Examining the presence of Salmonella spp. and $S$. aureus in raw and semi-cooked meat samples by Real-Time PCR analysis. Many methods are used to determine the presence of pathogenic microorganisms in food products. In addition to traditional methods, Real-Time PCR analysis method has become one of the most widely used analytical methods with its many benefits, such as being able to detect microorganisms in low concentrations and being fast and reliable (25). In our study, Real-Time PCR analysis was therefore the preferred method for detecting the presence of pathogenic microorganisms.

The numeric distribution of Salmonella and S. aureus found in each type of sample is displayed in Table 2. S. aureus was the most frequent contaminant of all types of samples. However, meat products containing $5.0 \times 10^{3} \mathrm{cfu} / \mathrm{g}$ or more microorganisms of $S$. aureus are considered to be inappropriate for consumption according to the Communique on Raw and Prepared Poultry Meat Mixture (26221) published

Tab. 2. Proportional distribution of microorganisms in examined samples

\begin{tabular}{|l|c|c|c|}
\hline \multirow{2}{*}{ Product type } & $\begin{array}{c}\text { The number } \\
\text { of samples }\end{array}$ & $\begin{array}{c}\text { The number of detected microorganisms } \\
\text { by Real-Time PCR } \\
\text { Salmonella } \\
\text { spp. }\end{array}$ & $\begin{array}{c}\text { S. aureus } \\
\left(5.0 \times 10^{3}-3 \times 10^{4} \text { cfu/g) }\right.\end{array}$ \\
\hline \multicolumn{2}{|r|}{ Raw meat } & 6 & 5 \\
Chicken meat & $25^{\mathrm{a}}$ & 6 & 2 \\
\hline Red meat & $25^{\mathrm{a}}$ & - & 5 \\
\multicolumn{2}{|c|}{ Semi-cooked } & & - \\
Chicken meat & $25^{\mathrm{b}}$ & - & 12 \\
\hline Red meat & $25^{\mathrm{b}}$ & - & 5 \\
\hline Total & 100 & 6 & \\
\hline
\end{tabular}

Explanations: ${ }^{\text {a }}$ - Samples were collected as 5 from bazaars, 10 from local markets and 10 from hypermarkets; ${ }^{b}$ - Samples were collected as 10 from local markets and 15 from hypermarkets 
by the Turkish Food Codex. We observed $S$. aureus as more than $5.0 \times 10^{3} \mathrm{cfu} / \mathrm{g}$ bacteria in 5 of 25 raw chicken samples, 2 of the 25 raw red meat samples, and 5 of 25 semi-cooked chicken meat samples (Tab. 2). Therefore, according to these standards, a total of twelve samples were determined as unsuitable. In the present study, out of a total of fifty raw samples, six $(27.3 \%)$ raw chicken meat samples were found to be contaminated with Salmonella. In contrast to raw chicken meat samples, no contamination was observed in red raw meat samples and semi-cooked meat samples. Even if a very low level of Salmonella is detected in food, the nutrient is considered to be in the risk group. According to the Communique on Raw and Prepared Poultry Meat Mixture (26221) and Regulation on Microbiological Criteria (28157) published by the Turkish Food Codex, the presence of Salmonella spp. in food groups should be zero $(0 / 25$ $\mathrm{g}-\mathrm{mL}$ ) so those samples were determined as inappropriate for consumption. Additionally, Regulation (EC) No 2160/2003 remarks that fresh poultry meat can be placed on the markets if Salmonella is absent in 25 grams of meat.

Many researchers have focused on the presence of pathogen microorganisms such as Salmonella spp. and $S$. aureus in different kinds of meat samples. Our data showed that in all of the samples, the rate of Salmonella spp. was $6 \%$ while $S$. aureus more than $5.0 \times 10^{3} \mathrm{cfu} / \mathrm{g}$ was $12 \%$. In many studies conducted in Turkey or abroad, the reported contamination ratios with Salmonella spp. and $S$. aureus have varied widely $(46,48,49)$. Greeson et al. (14) reported that $10.7 \%$ of various meat sources were contaminated with Salmonella. In another study by Akbar and Anal (2), $5.26 \%$ of poultry meat samples were shown to be contaminated with Salmonella while $18.18 \%$ were contaminated with $S$. aureus. Our results are similar to the values of those results. Moreover, in research conducted in Afyonkarahisar province in the west of Turkey, Salmonella presence was found to be 3\% in chicken meat and giblets samples (1). Also, our $S$. aureus prevalence is similar to various studies. For instance, Heo et al. (19) reported that $11 \%$ of meat samples were contaminated with $S$. aureus while De Boer et al. (10) reported that $16 \%$ of chicken meat samples were contaminated with $S$. aureus.

Staphylococcus-induced food poisoning occurs due to the fact that these microorganisms produce heatresistant enterotoxins. However, toxin production in the microorganism is present when the total number of cells in one gram of meat reaches 100,000 . In the samples analysed, $S$. aureus could not be detected at the level that could produce enterotoxins, but in a study in which 225 meat samples were collected from Ankara, $S$. aureus with enterotoxigenic properties was found in $77.1 \%$ of samples (34).

The rate of both Salmonella (0/50) and $S$. aureus $(5 / 50)$ contamination in semi-cooked meat samples was much lower than in raw meat samples. We interpret the presence of a lower number of microorganisms in semi-cooked meat products as a result of the heat treatment of these products during the fabrication phase. Taking into account all the samples used in our study, Salmonella was only observed in raw chicken meat samples. Unfortunately, raw chicken meat samples purchased from bazaars contained more Salmonella than purchased from local markets and hypermarkets. Similar to our results, Zwe et al. (50) found that the prevalence of Salmonella in chicken meat from wet markets was higher than in supermarkets. Another study conducted with meat samples collected at wetmarkets in Cambodia showed that nearly half of the samples were contaminated with both Salmonella and S. aureus (39).

The results obtained were not suitable for public health in terms of pathogenic microorganisms. In this case, it is thought that contamination stems from some hygiene problems during the process of cutting, washing, freezing, or during storage between the production steps of the supplier and the sale of food products (36). Therefore, the conditions in both production and transfer for markets should be improved for raw meat products (45).

Antibiotic resistance profile. Our Real-Time PCR analysis results show that five samples of raw chicken meats, two of raw red meats, and five of semi-cooked chicken meat were contaminated with $S$. aureus, versus six samples of raw chicken meats contaminated by Salmonella. Following qPCR, microorganisms were isolated using selective culture methods and biochemical tests from the meat samples that were verified to be contaminated with Salmonella and S. aureus (more than $5.0 \times 10^{3} \mathrm{cfu} / \mathrm{g}$ ) by Real-Time PCR analysis. Afterwards, antibiotic susceptibility of Salmonella spp. and $S$. aureus isolates was determined by Kirby-Bauer Disk Diffusion Method using 10 different antibiotics (4). Disk diffusion method is a fast and reliable method for detecting the resistance of bacteria to various antibiotics. For this reason, disc diffusion method was preferred for determining the antibiotics that can be used in the treatment of infections caused by isolated pathogenic microorganisms. The antibiotic resistance rates for the whole isolates are presented in Table 3. The response of Salmonella spp. and S. aureus microorganisms to tetracycline and oxytetracycline antibiotics was significantly different $(\mathrm{p}<0.05)$.

To date, many studies have been performed in the area of Salmonella identification, antibiotic resistance and molecular characterisation. As shown in Table 3, Salmonella had a high level of resistance to penicillin G $(100 \%)$, sulfamethoxazole $(83.33 \%)$, erythromycin $(66.66 \%)$, and ampicillin $(66.66 \%)$. These results are in agreement with the findings of similar studies on meat products from Thailand (2), Thailand-Cambodia (44), China (48), Iraq (17), Argentina (36), Egypt $(12,41)$, and South Korea (21). Our findings are also 
Tab. 3. Antibiotic resistance profile

\begin{tabular}{|c|c|c|c|c|c|c|c|}
\hline \multirow{3}{*}{ Type of antibiotic discs } & \multicolumn{6}{|c|}{ Amount of microorganisms } & \multirow{3}{*}{$P$ value } \\
\hline & \multicolumn{3}{|c|}{ Salmonella spp. (total $n=6$ ) } & \multicolumn{3}{|c|}{ S. aureus (total $\mathrm{n}=12$ ) } & \\
\hline & $\begin{array}{c}\text { Susceptible } \\
\text { n (\%) }\end{array}$ & $\begin{array}{c}\text { Intermediate } \\
\text { n (\%) }\end{array}$ & $\begin{array}{c}\text { Resistant } \\
\text { n (\%) }\end{array}$ & $\begin{array}{c}\text { Susceptible } \\
\text { n (\%) }\end{array}$ & $\begin{array}{c}\text { Intermediate } \\
\mathrm{n}(\%)\end{array}$ & $\begin{array}{c}\text { Resistant } \\
\text { n (\%) }\end{array}$ & \\
\hline Chloramphenicol & $5(83.33)$ & $1(16.66)$ & $0(-)$ & $12(100)$ & $0(-)$ & $0(-)$ & 0.35 \\
\hline Penicillin G & $0(-)$ & $0(-)$ & $6(100)$ & $0(-)$ & $2(16.66)$ & $10(83.33)$ & 0.58 \\
\hline Bacitracin & $5(83.33)$ & $0(-)$ & $1(16.66)$ & $10(88.33)$ & $0(-)$ & $2(16.66)$ & 0.99 \\
\hline Oxytetracycline & $6(100)$ & $0(-)$ & $0(-)$ & $0(-)$ & $3(25)$ & $9(75)$ & 0.0001 \\
\hline Sulfamethoxazole & $0(-)$ & $1(16.66)$ & $5(83.33)$ & $0(-)$ & $2(16.66)$ & $10(83.33)$ & 0.99 \\
\hline Neomycin & $4(66.66)$ & $2(33.33)$ & $0(-)$ & $11(91.66)$ & $1(8.33)$ & $0(-)$ & 0.41 \\
\hline Novobiocin & $4(66.66)$ & $2(33.33)$ & $0(-)$ & $10(83.33)$ & $2(16.66)$ & $0(-)$ & 0.72 \\
\hline Tetracycline & $6(100)$ & $0(-)$ & $0(-)$ & $0(-)$ & $3(25)$ & $9(75)$ & 0.0001 \\
\hline Erythromycin & $0(-)$ & $2(33.33)$ & $4(66.66)$ & $1(8.33)$ & $1(8.33)$ & $10(83.33)$ & 0.35 \\
\hline Ampicillin & $0(-)$ & $2(33.33)$ & $4(66.66)$ & $0(-)$ & $0(-)$ & $12(100)$ & 0.11 \\
\hline
\end{tabular}

similar to those in another study performed on chicken meat samples in Anatolia in terms of a high susceptibility percentage for chloramphenicol antibiotic of Salmonella (49). In contrast, resistance of Salmonella isolates from retail chicken and beef in Iran of 4\% to ampicillin were significantly lower than our result (8). Although our results for sulfamethoxazole are compatible with the Salmonella resistance profile obtained from frozen chicken samples in Bangladesh, the resistance percentages they observed for oxytetracycline and tetracycline do not support our results (35).

Pathogenic bacteria like $S$. aureus from different kinds of meat sources have been studied by many researchers all around the world. According to Table 3, $S$. aureus isolates show the highest resistance to ampicillin $(100 \%)$. In addition, they were the most frequently resistant to penicillin G $(83.33 \%)$, sulfamethoxazole $(83.33 \%)$, erythromycin $(83.33 \%)$, tetracycline $(75 \%)$, and oxytetracycline $(75 \%)$. Our findings are in compatible with the results of studies carried out in Turkey (5), Jordan (38), Saudi Arabia (14), Egypt (32), Bangladesh (9), Iran (18, 31), China $(29,47)$, and India (42). Our results reported that $S$. aureus isolates displayed a higher resistance percentage for tetracycline $(44.73 \%)$ and ampicillin $(55.26 \%)$ than the study in Thailand (2). Even though our resistance results are higher for penicillin, ampicillin, and erythromycin in $S$. aureus isolates, a study in Washington on meat products supports our findings for tetracycline and chloramphenicol (26). S. aureus isolates show the highest susceptibility for chloramphenicol. These findings are supported by studies in Louisiana (37) and Iran (3).

In this study, the presence and antibiotic resistance of food poisoning related pathogens Salmonella and $S$. aureus were researched among different meat products. The alteration of Salmonella and S. aureus contamination levels both in our study and others can be derived from the number of samples studied, detec- tion methods utilised, and cross-contamination during fabrication, processing or transferring. In addition, by being more careful about storing raw and semi-cooked products in separate cabinets, possible contaminations can be reduced. The incidence of $S$. aureus and Salmonella in examined samples was observed to be higher in raw meat products than semi-cooked meat products. Due to the heat treatment for semi-cooked meat products, we supposed that food-related pathogen presence decreases during fabrication. Also, cooking procedures should be applied effectively at home for raw products. It can be concluded that prevention of foodborne diseases depends on hygienic conditions and cold storage during the production and marketing stages of meat products. This study also suggests the necessity for the application of the HACCP (Hazard Analysis and Critical Control Point) food safety system, which determines the hygiene principles for healthy food production and increases the quality by ensuring product safety.

Apart from the presence of pathogens in our samples, resistance to different antibiotic agents was accompanied to microorganisms. Increased antibiotic resistance of microorganisms is a cause of concern for public health. Antibiotic resistance enables bacteria which is why it decreases the treatment of infections. The difference in resistance to antibiotics among microorganisms may be due to the unconscious use of antibiotics and quick change in antibiotic susceptibility profiles of bacteria within a brief period. In this study, it is thought that the antibiotic resistances obtained in microorganisms occur because of the unconscious usage of antibiotics in both human and animal diseases. Especially, $\beta$-Lactams are widely used antibiotics to treat infections, but using those antibiotics may result in the formation of resistant strains. Our study highlights the importance of conscious antibiotic usage in animal farming to increase consumer safety. Furthermore, since pathogenic bacteria pose a higher 
risk for young children, the elderly, and patients undergoing treatment, it is thought that a selective and conscious treatment may be more beneficial for them. Consequently, more restrictive politics should be taken into consideration and applied without discrimination to improve the current situation.

\section{References}

1.Acaroz U., Gurler Z., Kara R., Arslan-Acaroz D., Zemheri F.: Presence of Salmonella spp. in Chicken Meat and Giblets Marketed in Afyonkarahisar Province. Kocatepe Vet. J. 2018, 11, 414-418.

2. Akbar A., Anal A. K.: Prevalence and antibiogram study of Salmonella and Staphylococcus aureus in poultry meat. Asian Pac. J. Trop. Biomed. 2013, 3, 163-168.

3. Baghbaderani Z. T., Shakerian A., Rahimi E.: Phenotypic and Genotypic Assessment of Antibiotic Resistance of Staphylococcus aureus Bacteria Isolated from Retail Meat. Infect. Drug Resist. 2020, 13, 1339.

4. Bauer A. U., Kirby W. M., Sherris J. C., Turck M.: Antibiotic susceptibility testing by a standardized single disc method. Am. J. Clin. Pathol. 1966 493-496.

5. Can H. Y., Elmall M., Karagöz A.: Molecular typing and antimicrobial susceptibility of Staphylococcus aureus strains isolated from raw milk, cheese, minced meat, and chicken meat samples. Korean J. Food Sci. Anim. Resour. 2017, 37, 175 .

6. Chrobak D., Swida M. K., Rzewuska M., Binek M.: Antibiotic resistance of canine Staphylococcus intermedius group (SIG) - practical implications. Pol. J. Vet. Sci. 2011, 14, 213-218.

7. CLSI: Performance Standards for Antimicrobial Susceptibility Testing; Twenty-Fourth Informational Supplement. CLSI document M100-S24. Clinical and Laboratory Standards Institute, Wayne, PA 2014.

8.Dallal M. M. S., Doyle M. P., Rezadehbashi M., Dabiri H., Sanaei M., Modarresi S., Bakhtiari R., Sharifiy K., Taremi M., Zali M. R., Sharifi-Yazdi $M . K$ : Prevalence and antimicrobial resistance profiles of Salmonella serotypes, Campylobacter and Yersinia spp. isolated from retail chicken and beef, Tehran, Iran. Food Control. 2010, 21, 388-392.

9.Datta S., Akter A., Shah I. G., Fatema K., Islam T. H., Bandyopadhyay A., Khan Z. U. M., Biswas D.: Microbiological quality assessment of raw mea and meat products, and antibiotic susceptibility of isolated Staphylococcus aureus. Agric. Food Anal. Bacteriol. 2012, 2, 187-194.

10. De Boer E., Zwartkruis-Nahuis J. T. M., Wit B., Huijsdens X. W., De Neeling A. J., Bosch T., Van Oosterom R. A. A., Vila A., Heuvelink A. E.: Prevalence of methicillin-resistant Staphylococcus aureus in meat. Int. J. Food Microbiol. 2009, 134, 52-56.

11. Deepak S., Kottapalli K., Rakwal R., Oros G., Rangappa K., Iwahashi H. Real-Time PCR: Revolutionizing Detection and Expression Analysis of Genes. Curr. Genom. 2007, 8, 234-251.

12. Eid H. Helal I., Kouta R: Bacteriological studies on Salmonella isolated from balady chicken meat. Suez canal Vet. Med. J. (SCVMJ) 2020, 25, 105-114.

13. Filazi A.: Antibiotic Residues in Food of Animal Origin and Evaluating of Their Risks. Turkiye Klinikleri J. Vet. Sci. 2012, 3, 1-7.

14. Greeson K., Suliman G. M., Sami A., Alowaimer A., Koohmaraie M. Frequency of antibiotic resistant Salmonella, Escherichia coli, Enterococcus, and Staphylococcus aureus in meat in Saudi Arabia. Afr. J. Microbiol. Res. 2013, 7, 309-316.

15. Gundogan N., Citak S., Yucel N., Devren A.: A note on the incidence and antibiotic resistance of Staphylococcus aureus isolated from meat and chicken samples. Meat Sci. 2005, 69, 807-810.

16. Guner A., Atasever M., Aydemir A. M.: New Emerging and Re-Emerging Bacterial Foodborne Pathogens. Kafkas Univ. Vet. Fak. Derg. 2012, 18, 889-898.

17. Harb A., Habib I., Mezal E. H., Kareem H. S., Laird T., O'Dea M., Abraham S Occurrence, antimicrobial resistance and whole-genome sequencing analysis of Salmonella isolates from chicken carcasses imported into Iraq from four different countries. Int. J. Food Microbiol. 2018, 284, 84-90.

18. Hasanpour Dehkordi A., Khaji L., Sakhaei Shahreza M. H., Mashak Z., Safarpoor Dehkordi F., Safaee Y., Hosseinzadeh A., Alavi I., Ghasemi E. Rabiei-Faradonbeh M.: One-year prevalence of antimicrobial susceptibility pattern of methicillin-resistant Staphylococcus aureus recovered from raw meat. Trop. Biomed. 2017, 34, 396-404.

19. Heo H. J., Ku B. K., Bae D. H., Park C. K., Lee Y. J.: Antimicrobial resistance of Staphylococcus aureus isolated from domestic and imported raw meat in Korea. Korean J. Vet. Res. 2008, 48, 75.
20. Hughes C., Gillespie I. A., O'Brien S. J.: Foodborne transmission of infectious intestinal disease in England and Wales 1992-2003. Food Control 2007, 18, 766-772.

21. Hyeon J., Chon J., Hwang I., Kwak H., Kim H., Kim S.: Prevalence, antibiotic resistance, and molecular characterization of Salmonella serovars in retail meat products. J. Food Prot. 2011, 74, 161-166.

22. Hyeon J. Y., Park J. H., Chon J. W., Wee S. H., Moon J. S., Kim Y. J., Seo $K$. H.: Evaluation of selective enrichment broths and chromogenic media for Salmonella detection in highly contaminated chicken carcasses. Poult. Sci. 2012, 91, 1222-1226

23. Iseri $O$., Erol I.: The main bacterial infections and intoxications related to turkey meat. Ankara Univ. Vet. Fak. Derg. 2009, 56, 47-54.

24. Kania B. F., Kania K.: Pharmacological and toxicological aspects of combination of beta-lactam and aminoglycoside antibiotic, prednisolone and procaine hydrochloride on the example of Vetramycin. Pol. J. Vet. Sci. 2003, 6, 279-296.

25. Kahya S., Yilmaz O., Carli K. T.: Advantages of Real-Time PCR than Conventional PCR in Diagnosis of Infectious Animal Disease. Uludag Univ. Vet. Fak. Derg. 2013, 32, 39-44.

26. Kelman A., Soong Y. A., Dupuy N., Shafer D., Richbourg W., Johnson K., Brown T., Kestler E., Li Y., Zheng J., Mcdermott P., Meng J.: Antimicrobial susceptibility of Staphylococcus aureus from retail ground meats. J. Food Prot. 2011, 74, 1625-1629.

27. Khan A., Melvin C., Dagdag E.: Identification and molecular characterization of Salmonella spp. from unpasteurized orange juices and identification of new serotype Salmonella strain S. enterica serovar Tempe. Food Microbiol. 2007, 24, 539-543.

28. Klotz M., Opper S., Heeg K., Zimmermann S.: Detection of Staphylococcus aureus enterotoxins A to D by real-time fluorescence PCR assay. J. Clin. Microbiol. 2003, 41, 4683-4687.

29. Li S., Wang P., Zhao J., Zhou L., Zhang P., Fu C., Meng J., Wang X. Characterization of toxin genes and antimicrobial susceptibility of Staphylococcus aureus from retail raw chicken meat. J. Food Prot. 2018, 81, 528-533.

30. Malorny B., Paccassoni E., Fach P., Bunge C., Martin A., Helmuth R. Diagnostic real-time PCR for detection of Salmonella in food. Appl. Environ. Microbiol. 2004, 70, 7046-7052.

31. Momtaz H., Dehkordi F. S., Rahimi E., Asgarifar A., Momeni M.: Virulence genes and antimicrobial resistance profiles of Staphylococcus aureus isolated from chicken meat in Isfahan province, Iran. J. Appl. Poult. Res. 2013, 22, 913-921.

32. Osman K., Alvarez-Ordonez A., Ruiz L., Badr J., ElHofy F., Al-Maary K. S., Moussa I. M. I., Hessain A. M., Orabi A., Saad A., Elhadidy M.: Antimicrobial resistance and virulence characterization of Staphylococcus aureus and coagulase-negative staphylococci from imported beef meat. Ann. Clin. Microbiol. Antimicrob. 2017, 16, 35.

33. Oz V., Karadayi S., Cakan H., Karadayı B., Kaya A.: Food poisoning in emergency units. Marmara Med. J. 2014, 27, 89-95.

34. Ozdemir H., Keyvan E.: Isolation and characterisation of Staphylococcus aureus strains isolated from beef, sheep and chicken meat. Ankara Univ. Vet. Fak. Derg. 2016, 63, 333-338.

35. Parvin M. S., Hasan M. M., Ali M. Y., Chowdhury E. H., Rahman M. T., Islam M. T.: Prevalence and Multidrug Resistance Pattern of Salmonella Carrying Extended-Spectrum $\beta$-Lactamase in Frozen Chicken Meat in Bangladesh. J. Food Prot. 2020, 83, 2107-2121.

36. Procura F., Bueno D. J., Bruno S. B., Rogé A. D.: Prevalence, antimicrobial resistance profile and comparison of methods for the isolation of Salmonella in chicken liver from Argentina. Food Res. Int. 2019, 119, 541-546.

37. Pu $S$., Wang $F$. Ge B.: Characterization of toxin genes and antimicrobial susceptibility of Staphylococcus aureus isolates from Louisiana retail meats. Foodborne Pathog. Dis. 2011, 8, 299-306.

38. Quddoumi S. S., Bdour S. M., Mahasneh A. M.: Isolation and characterization of methicillin-resistant Staphylococcus aureus from livestock and poultry meat. Ann. Microbiol. 2006, 56, 155-161.

39. Rortana C., Grace D., Nguyen-Viet H., Tum S., Dang-Xuan S., Theary R., Sophary S., Koam S., Pheany S., Sotheany H., Heng T., Sarim S., Lindahl J.: Prevalence of Salmonella and Staphylococcus aureus from meat in Cambodian markets. Conference: Regional symposium on research into smallholder pig production, health, and pork safety Hanoi, 27-29 March 2019.

40. Sağlam D., Seker E.: Food-borne Bacterial Pathogens. Kocatepe Vet. J. 2016, 9, 105-113.

41. Sallam K. I., Mohammed M. A., Hassan M. A., Tamura T.: Prevalence, molecular identification and antimicrobial resistance profile of Salmonella serovars isolated from retail beef products in Mansoura, Egypt. Food Control 2014, 38, 209-214.

42. Savariraj W. R., Ravindran N. B., Kannan P., Paramasivam R., Senthilkumar T. M. A., Kumarasamy P., Rao V. A.: Prevalence, antimicrobial susceptibility 
and virulence genes of Staphylococcus aureus isolated from pork meat in retail outlets in India. J. Food Saf. 2019, 39, e12589.

43. Thapaliya D., Forshey B., Kadariya J., Quick M., Farina S., O'Brien A. Prevalence and molecular characterization of Staphylococcus aureus in commercially available meat over a one-year period in Iowa, USA. Food Microbiol. 2017, 65, 122-129.

44. Trongjit S., Angkititrakul S., Tuttle R. E., Poungseree J., Padungtod P. Chuanchuen R.: Prevalence and antimicrobial resistance in Salmonella enterica isolated from broiler chickens, pigs and meat products in Thailand-Cambodia border provinces. Microbiol. Immunol. 2017, 61, 23-33.

45. Tonbak F., Atasever M., Calıcıoglu M.: Salmonella Risk in Poultry Meat. Atatürk Üniversitesi Vet. Bil. Derg. 2017, 12, 90-98.

46. Van T. T., Moutafis G., Istivan T., Tran L. T., Coloe P. J.: Detection of Salmonella spp. in retail raw food samples from Vietnam and characterization of their antibiotic resistance. Appl. Environ. Microbiol. 2007, 73, 6885-6890.

47. Wu S., Huang J., Wu Q., Zhang J., Zhang F., Yang X., Wu H., Zeng H., Chen M., Ding Y., Wang J., Lei T., Zhang S., Xue L.: Staphylococcus aureus isolated from retail meat and meat products in China: incidence, antibiotic resistance and genetic diversity. Front. Microbiol. 2018, 9, 2767.

48. Yang B., Qu D., Zhang X., Shen J., Cui S., Shi Y.: Prevalence and characterization of Salmonella serovars in retail meats of marketplace in Shaanxi, China. Int. J. Food Microbiol. 2010, 141, 63-72.

49. Yuksel M., Cetin B., Sert S.: Determination of Microbiological Quality and Presence of Salmonella spp. on Chicken Parts Sold at Retail Markets in Erzurum, Antibiotic Resistance of the Salmonella spp. Isolates. Gida. 2019, 44, 553-562.

50.Zwe Y. H., Tang V. C. Y., Aung K. T., Gutiérrez R. A., Ng L. C., Yuk H. G. Prevalence, sequence types, antibiotic resistance and, gyrA mutations of Salmonella isolated from retail fresh chicken meat in Singapore. Food Control. 2018, 90, 233-240

Corresponding author: Prof. Dr. Reyhan Irkin, Izmir Democracy University, Faculty of Health Sciences, Department of Nutrition and Dietetics, Guzelyali, Konak TR35290, Izmir, Turkey; e-mail: reyhan.irkin@idu.edu.tr 